\title{
Epicardial Fat Thickness as a Diagnostic Marker of Coronary Lesions in Stable Angina Pectoris Patients.
}

\author{
Ulzim Fajar ${ }^{1}$, Mefri Yanni ${ }^{2}$, Muhammad Syukri ${ }^{3}$
}

' Cardiology Resident of RSUP DR M Djamil Hospital - Medical Faculty of Andalas University, Padang, Sumatera Barat, Indonesia.

${ }^{2}$ Supervisor of non-Invasive Diagnostic and Imaging SubDivision, DR M Djamil HospitalAndalas University, Padang, Sumatera Barat, Indonesia.

${ }^{3}$ Supervisor of Invasive Diagnostic and Intervention Cardiology SubDivision, DR M Djamil HospitalAndalas University, Padang, Sumatera Barat, Indonesia.

\section{Correspondence:}

Ulzim Fajar

Medical Faculty of Andalas

University, Padang, Sumatera Barat, Indonesia.

Email: ulzimparsel@gmail.com

\begin{abstract}
Background: Abdominal visceral adiposity is a risk factor of cardiovascular diseases. It correlates with increasing level of pro-inflammatory adipokines and cytokines which can induce endothelial dysfunction. Epicardial adipose tissue is considered as true visceral adiposity of the heart. Epicardial adipose tissue have pivotal role than other visceral adiposity because of adjacency to the heart and coronary vessels. This study was aimed to measure the cut off point of epicardial fat thickness as a diagnostic marker for the presence of coronary lesion.

Methods: This was an observational analytic study with crossectional comparative design. Data was retrieved prospectively at the Heart Center Dr. M. Djamil Padang from August 2019 to February 2020 in stable angina pectoris patients who underwent coronary angiography. The Epicardial Fat Thickness (EFT) was measured at end-diastole from the Parasternal long axis (PLAX) views of three cardiac cycles on the free wall of the right ventricle on echocardiography examination. Bivariate analysis was used to assess epicardial fat thickness and presence of the coronary lesions using Independent Sample $T$ test. A diagnostic test was performed based on receiver operating curve (ROC) analysis.
\end{abstract}

Results: Patients were diagnosed as CAD group group $(n=150 ; 58.1 \mathrm{I} \pm$ 8.24 years) and non-CAD group $(n=50 ; 53.16 \pm 9.78$ years) based on coronary angiogram result. Epicardial fat thickness was higher in subjects with coronary lesions $(3.62 \pm 1.03 \mathrm{~mm}$ ) compared with subjects without coronary lesions ( $1.55 \pm \mathrm{I} .10 \mathrm{~mm}$ ) with $\mathrm{p}<0.00 \mathrm{I}$. Epicardial fat thickness $\geq 2.835 \mathrm{~mm}$ predict the presence of coronary lesion by $82 \%$ sensitivity, $86 \%$ specificity and $88.9 \%$ accuracy based on the AUC value.

Conclusion: Abnormal epicardial fat thickness $\geq 2.835 \mathrm{~mm}$ can be a good diagnostic marker to detect the presence of coronary lesion.

(Indonesian J Cardiol. 2020;4I: 199-205)

Keywords: epicardial fat thickness; coronary artery lesions; stable angina pectoris 


\section{Introduction}

A therosclerosis is well known as chronic inflammation in arterial wall. It iniate and propagate lesion formation in arterial wall was responsible to the proinflammation metabolic profile and lead to this chronic inflammation. It process through released proinflammatory cytokines by visceral adipocytes and lead to systemic low grade inflammation. ${ }^{1}$

Epicardial adipose tissue was considered as true of visceral adipocity of the heart because of several factors. Epicarial adipose tissue predominantly with contain preadipocyte, It have endocrine phenotype dominant than mature adipocyte. Furthermore, epicardial adipose tissue have same origin as abdominal visceral adipose tissue. Both of it have arise from splanchinopleuric mesoderm origin embryologically. Epicardial adipocyte got blood circulation from microbranchs of coronary arteries and there was no any structure or fascia which separated epicardial adipose tissue to the cardiomyocyte and coronary artery. Based on aforementioned, the proinflammatory cytokines that released by epicardial adipocytes can impact directly to the coronary artery via vasocrine and paracrine. ${ }^{2}$ Nagy E et al proved that in patients with coronary artery patients, their epicardial adipose tissue have increase of proinflammatory mediator like (Interleukin-6, TNF- $\alpha$, interleukin-1 $\beta$, monocyte chemoattractant protein-1 (MCP-1)), macrofag, limphocytes and basophile than subcutaneous adipose tissue. $^{3}$

\section{Methods}

This study was analytic observational with crossectional comparative design. First group was subject with coronary lesion, and second group was without coronary lesion. This study was conducted at the integrated Heart Services Installation RSUP Dr. M. Djamil Padang from August 2019-February 2020.

Subject of this study was all of the patient who were diagnosed as stable angina pectoris and underwent elective coronary angioplasty. Inclusion criteria were patient with normal breathing pattern, and normal sinus rhythm. Exclusion criteria were patient with severe valves disease, intracardiac defect, pericardial effusion, left pleural effusion, suboptimal echo window, and history of coronary stenting.

Sampling was done by convenience sampling. All of subject underwent transthoracal echocardiography by echomachine. Epicardial fat thickness was measured at parasternal long axis (PLAx) view, in left lateral decubitus position, in line with aortic valve as a marker of cursor beam, in end-diastolic phase. Measurement was done three times and the average of the value was taken as final result. ${ }^{4}$

Coronary lesion was defined as stenosis of epcardial coronary vessel $\geq 20 \% .^{5}$ Lesion was measured independently by coronary angiography operator and blind with the echocardiography result.

\section{Results}

Patients were diagnosed as CAD group group (n $=150)$ and non-CAD group $(n=50)$ based on coronary angiogram result.

Based on table 1 it was known that there were statistically significant differences on variables of age, sex, smoking, menopause, waist circumference, epicardial fat thickness and administration of antiplatelet and long-acting nitrate therapy between the coronary lesion group and without coronary lesion $(\mathrm{p}<0.05)$.

Assessment the heterogeneity of subjects characteristics of coronary lesions using the MantelHaenszel test on discrete data and the Levene test on continuous data to see uniformity. There were no confounding variables between study groups. Based on the heterogeneity assessment of the characteristics of respondents with coronary lesions, age, sex, body mass index, waist circumference, epicardial fat thickness, and each drug therapy are homogeneous. Meanwhile risk factor variables were heterogeneous between groups with lesions and no lesions. So it can be said that cardiovascular risk factors such as smoking, dyslipidemia, diabetes, hypertension, menopause, family history can be confounding factors in this study after heterogeneity data testing.

The cut off point value of the optimal sensitivity and specificity line can be seen in Table 2 .

Based on table 2 it was known that the cut off point epicardial fat thickness predicting the determination of coronary lesions in stable angina pectoris patients was at 
Indonesian Journal of Cardiology

Table 1 Baseline Characteristic Subjects

\begin{tabular}{|c|c|c|c|}
\hline \multirow[b]{2}{*}{ Variables } & \multicolumn{2}{|c|}{ Groups } & \multirow[b]{2}{*}{ P value } \\
\hline & $\begin{array}{c}\text { CAD } \\
(n=150)\end{array}$ & $\begin{array}{c}\text { Non-CAD } \\
(\mathrm{n}=50)\end{array}$ & \\
\hline Age (year), mean $\pm S D \#$ & $58.11 \pm 8.24$ & $53.16 \pm 9.78$ & $0.001 \mathrm{~b}^{*}$ \\
\hline Sex, n (\%)\# & & & $<0.001 \mathrm{a}^{*}$ \\
\hline Male & $116(77.3)$ & $21(42.0)$ & \\
\hline Female & $34(22.7)$ & $29(58.0)$ & \\
\hline \multicolumn{4}{|l|}{ Risk factors, n (\%) } \\
\hline Family history & $8(5.3)$ & $6(12.0)$ & $0.119 \mathrm{a}$ \\
\hline Smoker & $84(56.0)$ & $15(30.0)$ & $0.003 \mathrm{a}^{*}$ \\
\hline Dyslipidemia & $57(38.0)$ & $15(30.0)$ & $0.395 \mathrm{a}$ \\
\hline Total cholesterol, Me (Min-Max) & $178.5(93-312)$ & $167(91-226)$ & $0.055 c$ \\
\hline Trigliserida, Me (Min-Max) & $138.5(32-365)$ & $112(56-260)$ & $<0.001 c^{*}$ \\
\hline LDL, Me (Min-Max) \# & $115(47-219)$ & $102(44-169)$ & $0.073 \mathrm{c}$ \\
\hline HDL, Me (Min-Max) \# & $40(25-76)$ & $43(21-88)$ & $0.033 c^{*}$ \\
\hline Hypertension & $102(68.0)$ & $27(54.0)$ & $0.105 \mathrm{a}$ \\
\hline Menopause & $29(19.3)$ & $18(36.0)$ & $0.027 \mathrm{a}^{*}$ \\
\hline Diabetes & $31(20.7 \%)$ & $7(14.0)$ & $0.405 \mathrm{a}$ \\
\hline BMI $(\mathrm{kg} / \mathrm{m} 2)$, mean \pm SD\# & $25.45 \pm 2.97$ & $25.22 \pm 3.68$ & $0.649 \mathrm{~b}$ \\
\hline BMI categories, n (\%) & & & $0.664 \mathrm{a}$ \\
\hline Normoweight & $30(20)$ & $13(26)$ & \\
\hline Overweight & $38(25.3)$ & $9(18)$ & \\
\hline Obese I & $72(48)$ & $24(48)$ & \\
\hline Obese II & $10(6.7)$ & $4(8)$ & \\
\hline Waist circumference $(\mathrm{cm})$, mean $\pm S D \#$ & $95.18 \pm 8.82$ & $87.53 \pm 10.73$ & $<0.001 \mathrm{~b}^{*}$ \\
\hline Male\# & $96.29 \pm 8.42$ & $92.57 \pm 12.05$ & $0.085 b$ \\
\hline Female\# & $91.37 \pm 9.19$ & $83.89 \pm 8.06$ & $0.001 b^{*}$ \\
\hline \multicolumn{4}{|l|}{ Waist circumference categories } \\
\hline Male, $\mathrm{n}(\%) \#$ & & & $0.010 \mathrm{a}^{*}$ \\
\hline abnormal & $90(77.6)$ & $10(47.6)$ & \\
\hline normal & $26(22.4)$ & $11(52.4)$ & \\
\hline Female, $\mathrm{n}(\%) \#$ & & & $0.006 \mathrm{a}^{*}$ \\
\hline abnormal & $31(91.2)$ & $17(58.6)$ & \\
\hline normal & $3(8.8)$ & $12(41.4)$ & \\
\hline Epicardial fat thickness\# $(\mathrm{mm})$, mean $\pm S D$ & $3.62 \pm 1.03$ & $1.55 \pm 1.10$ & $<0.001 \mathrm{~b}^{*}$ \\
\hline Normoweight\# & $3.57 \pm 0.94$ & $1.67 \pm 1.13$ & $<0.001 b^{*}$ \\
\hline Overweight & $3.46 \pm 1.11$ & $1.26 \pm 0.46$ & $<0.001 \mathrm{~b}^{*}$ \\
\hline Obese I\# & $3.71 \pm 1.02$ & $1.57 \pm 1.19$ & $<0.001 \mathrm{~b}^{*}$ \\
\hline Obese II\# & $3.77 \pm 1.19$ & $1.67 \pm 0.78$ & $0.023 \mathrm{~b}^{*}$ \\
\hline \multicolumn{4}{|l|}{ Medical therapies, $\mathrm{n}(\%)$} \\
\hline Antiplatelet\# & $149(99.3)$ & $40(80.0)$ & $<0.001 \mathrm{a}^{*}$ \\
\hline ACE-I/ARB\# & $135(90.0)$ & $40(80.0)$ & $0.109 \mathrm{a}$ \\
\hline Beta blocker\# & $133(88.7)$ & $43(86.0)$ & $0.802 \mathrm{a}$ \\
\hline Statin\# & $150(100.0)$ & $40(80.0)$ & $\mathrm{n} / \mathrm{a}$ \\
\hline Isosorbide dinitrate\# & $31(20.7)$ & $6(12.2)$ & $0.270 \mathrm{a}$ \\
\hline Long acting nitrate\# & $67(44.7)$ & $11(22.0)$ & $0.007 \mathrm{a}^{*}$ \\
\hline $\mathrm{CCB} \#$ & $44(29.3)$ & $11(22.0)$ & $0.411 \mathrm{a}$ \\
\hline
\end{tabular}

*, significant with p value $<0.05$

a, Chi-square test

$b$, Independent sample $T$ test

n/a, Not Available

c, Mann-whitney test

\#, data was homogen after heterogeneity data test

Abnomal waist circumference: male $>90 \mathrm{~cm}$, female $>80 \mathrm{~cm}$

LDL (Low Density Lipoprotein); HDL (High Density Lipoprotein); BMI (Body Mass Index 
Indonesian Journal of Cardiology

Table 2. cut-off values based on sensitivity and specificity of epicardial fat thickness predicting the determination of coronary lesions in patients with stable angina pectoris

\begin{tabular}{llcccc}
\hline No & \multicolumn{1}{c}{ Cut off Point } & Sensitivity & $\mathbf{1}$ - Specificity & Sensitivity & Specificity \\
\hline 1 & -0.33 & 1 & 1 & 1 & 0 \\
2 & 0.835 & 0.993333333 & 0.68 & 0.993333333 & 0.32 \\
3 & 1.165 & 0.98 & 0.5 & 0.98 & 0.5 \\
4 & 1.5 & 0.96 & 0.3 & 0.96 & 0.7 \\
5 & 1.835 & 0.94 & 0.24 & 0.94 & 0.76 \\
6 & 2.165 & 0.906666667 & 0.22 & 0.906666667 & 0.78 \\
7 & 2.5 & 0.886666667 & 0.16 & 0.886666667 & 0.84 \\
8 & 2.835 & 0.82 & 0.14 & 0.82 & 0.86 \\
9 & 3.165 & 0.72 & 0.14 & 0.72 & 0.86 \\
10 & 3.5 & 0.573333333 & 0.12 & 0.573333333 & 0.88 \\
11 & 3.835 & 0.4 & 0.1 & 0.4 & 0.9 \\
12 & 4.165 & 0.28 & 0.04 & 0.28 & 0.96 \\
13 & 4.5 & 0.18 & 0 & 0.18 & 1 \\
14 & 4.835 & 0.113333333 & 0 & 0.113333333 & 1 \\
15 & 5.165 & 0.06 & 0 & 0.06 & 1 \\
16 & 5.5 & 0.033333333 & 0 & 0.033333333 & 1 \\
17 & 5.835 & 0.02 & 0 & 0.02 & 1 \\
18 & 6.165 & 0.006666667 & 0 & 0.006666667 & 1 \\
19 & 7.33 & 0 & 0 & 0 & 1 \\
\hline
\end{tabular}

ACE: angiotensin-converting-enzyme; TIMI: Thrombolysis in Myocardial Infarction; pPCI: primary percutaneous coronary intervention * Bivariate analysis value that continue with multivariate linear regression analysis

8 point with a cut-off point of 2.835 , the determination of classification can be explained as follows:

a. Subjects with abnormal epicardial fat thickness, if $\geq 2.835$

b. Subjects with normal epicardial fat thickness, if $<2.835$

The accuracy of epicardial fat thickness predicting the determination of coronary lesions in patients with stable angina pectoris can be seen in Figure 4.2 below.

Figure 1. showed the value of the area under the curve (AUC) in the ROC analysis known to be $88.9 \%$, it can be concluded the accuracy of the thickness of epicardial fat in the determination of coronary lesions in patients with stable angina pectoris included in the category of good accuracy.

\section{Discussion}

Subjects with coronary lesions were found greater in men and without coronary lesions were greater in women. From statistical analysis, it was appropriate with the benefits obtained ( $\mathrm{p}<0.001)$. Cheng et al showed that men with typical angina have a greater risk for coronary heart disease with more severe lesions than women $(19 \%$ vs $11 \%, \mathrm{p}<0.001){ }^{6}$ A study involving

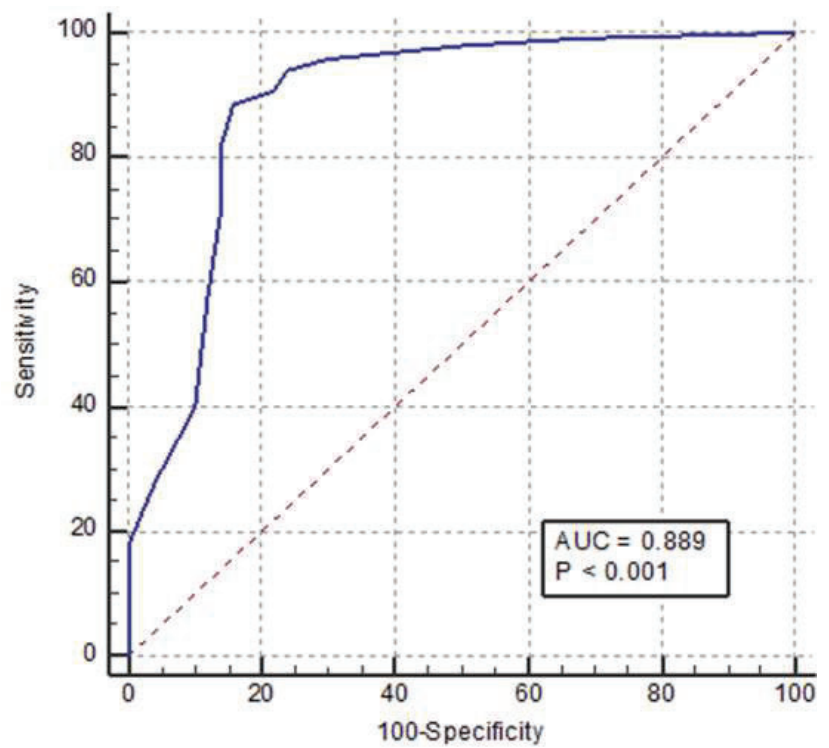

Figure 1. Accuracy of Epicardial Fat Thickness Predicting the Determination of Coronary Lesions in Stable Angina Pectoris Patients

14.786 subjects in Finland showed men have a 3-fold greater risk than women to get coronary heart disease with five time mortality risk. ${ }^{7}$

The mean age of coronary lesion subjects in this study was $58.11 \pm 8.24$ and $53.16 \pm 9.78$ years respectively 
without coronary lesions, where the group with coronary lesions had an older age, and was statistically significant $(\mathrm{p}=0.001)$. It was similar with the results by Shemirani $\mathrm{H}$ et al, in which subjects with coronary lesions had an older age compared to subjects without coronary lesions $(59 \pm 10 \mathrm{p}=0.02$ vs $54 \pm 8.6 ; \mathrm{p}=0.01) .{ }^{8}$ Old age was a cardiovascular risk factor that couldn't be modified . This was related to the degenerative process that causes a decrease of organ functional. ${ }^{\text {? }}$

Smoking were found to be statistically significant for coronary lesions. This is associated with coronary lesions in men was greater than women, because of smoking habits. Smoking has a negative effect in the form of decreased formation and bioavailability of nitric oxide, activation of pro-inflammatory genes and an increase in the component of oxidative stress that will lead into the initiation and progression of atherosclerosis. ${ }^{10}$

In this study epicardial fat thickness from the coronary lesion group was found to be significantly thicker than the group without coronary lesions. Similar results were obtained by some researchers such as Teresa $\mathrm{G}$ et al. $(5.39 \pm 1.75 \mathrm{~mm}$ vs. $4.00 \pm 1.67 \mathrm{~mm}$ $\mathrm{p}<0.0001)^{11}$ and Kamal D et al $(7.4 \pm 1.3$ vs $4.12 \pm$ $0.82<0.001)^{12}$ for the thick epicardial fat group with and without coronary lesions in sequence. Nabati $\mathrm{M}$ et al. also found a higher TLE in the group with coronary lesions compared to normal coronary ( $<<0.001,95 \%$ confidence interval)..$^{13}$ Research by Park JS et al found higher epicardial fat thickness in patients with coronary lesion groups compared without coronary lesions without body mass index at BMI $<27 \mathrm{~kg} / \mathrm{m} 2$ and BMI $\geq 27 \mathrm{~kg} / \mathrm{m} 2$ (3.5 vs. $1.5 \mathrm{~mm}, \mathrm{p}<0.001$ and 4.0 vs. $2.5 \mathrm{~mm}, \mathrm{p}=0.001$, respectively). ${ }^{14}$ Meanwhile Teresa et $a l$ and Kamal et al obtained higher values of epicardial fat thickness in subjects without coronary lesions rather than this study. This may be influenced by the race variation.

Chaowalit et al get different results, their study found that there was no significant difference in the mean thickness of epicardial fat in the group with coronary lesions compared to without coronary lesions $(2.17 \pm 1.84 \mathrm{~mm} \text { vs } 2.45 \pm 1.72 \mathrm{~mm}, \mathrm{p} 0.52)^{15}$ This was likely influenced by the number of samples without coronary lesions in the study. they were relatively small sample only $18(12.9 \%)$ of 139 samples.

In this study, the cut-off points of epicardial fat thickness in predicting coronary lesions was $2.835 \mathrm{~mm}$, serving EFT $<2.835 \mathrm{~mm}$ as a normal EFT and EFT $\geq$ $2.835 \mathrm{~mm}$ as a thicker EFT. This result has a sensitivity of $82 \%$, a specificity of $86 \%$, and has good accuracy $(88.9 \%)$ based on the AUC value. The sensitivity and specificity of this study are good. Thus, epicardial fat thickness with a cut point value of $2.835 \mathrm{~mm}$ can be used as an aid in predicting the presence of coronary lesions in patients with stable pectoral angina and in a screening for coronary lesions in patients without complaints of angina pectoris. One of a research which has been using the same EFT assessment method shows similar results in comparison to this study, including a study by Faghihi $e t a l$, which obtained a cut-off value of $2.96 \mathrm{~mm}$ with a sensitivity of $83 \%$, a specificity of $75 \%$, and an accuracy of $81 \% .{ }^{16}$ Furthermore, Eroglu et al., obtained a cut-off value of $5.2 \mathrm{~mm}$ with a sensitivity of $85 \%$, a specificity of $81 \%$, and an accuracy of $91.4 \% .{ }^{17}$ El-Aziz et al., get a cut-off point value of $5.2 \mathrm{~mm}$ with a sensitivity of $85 \%$, a specificity of $81 \%$, and an accuracy of $91 \% .^{18}$

These differences in cut-off points may be influenced by racial differences between study populations, given that epicardial fat thickness is also influenced by racial differences. ${ }^{1,2}$ A study by Faghihi et al., was conducted in Iranian population, Eroglu et al., in Turkish population, and El-Aziz et al., in Egyptians. However, until now there has been no large study comparing differences in the thickness of epicardial fat in different ethnicities. In general, the accumulation of visceral fat is higher in white ethnicities compared to black ethnicities. ${ }^{219}$ Epicardial fat tissue is visceral fat tissues of the heart which also seems to have the same pattern as ethnic variations. A study from Willens $\mathrm{HJ}$ found that epicardial fat thickness was higher in nonHispanic white ethnicity than African-American black ethnicity $\left(2.2 \pm 1.6 \mathrm{~mm}\right.$ vs $1.3 \pm 1.2 \mathrm{~mm}, \mathrm{p}<0.001 .^{20}$ Epicardial fat tissue was higher in South Asian ethnicity and Southeast Asia or East Asia compared to Caucasians $(103.2 \pm 41.7 \mathrm{~mm} 3,110.8 \pm 36.9 \mathrm{~mm} 3,85.8 \pm 39.4$ $\mathrm{mm} 3 ; \mathrm{p}=0.006) .{ }^{21}$ The differences in epicardial fat tissue deposits in various studies may be influenced by genetic roles. the data should explain this, but a research from Fox CS et al. found that out of 5487 multiethnic patients taken from the large Framingham Heart Study (FHS) and Multiethnic Study of Atherosclerosis (MESA), there was a unique locus of 10198628 in the TRIB2 gene (Tribbles) homolog 2 gene) associated with 
cardiac ectopic fat deposition, but not subcutaneous fat depots or other visceral fat depots. ${ }^{22}$

Another study by Kamal D et al. depicted a cut-off point value of $5.5 \mathrm{~mm}$ fat thickness with a sensitivity of $98 \%$, a specificity of $100 \%$, and an accuracy of $99.2 \%$ based on the AUC value, $p$-value $<0.001 .^{12}$ The sensitivity, specificity, and accuracy value by Kamal D et al. was higher than this study. This might be due to the basic characteristics of patients in the study, in which the group with coronary lesions had a significantly higher body mass index compared to the group without coronary lesions $(35.98 \pm 4.31$ vs $27.38 \pm 2.03$, p $<0.001$ ), in addition, those with coronary lesions also have a higher metabolic syndrome condition than those without coronary lesions (hypertension $88 \%$ vs $2 \% \mathrm{p}$ $<0.001$; diabetes $67 \%$ vs $0 \% \mathrm{p}<0.001$ and dyslipidemia $56 \%$ vs $0 \% \mathrm{p}<0.001)$. This is supported by the study of Jain $S$ et al. who found the mean value of EFT in diabetics with obesity significantly thicker than diabetic subjects without obesity $(10.2 \mathrm{~mm}$ and $5.92 \mathrm{~mm}$; p $<0.001)$. The thickness of this epicardial fat increases with increasing degrees of obesity $(5.92 \mathrm{~mm}, 7.43 \mathrm{~mm}$, $12.97 \mathrm{~mm}, 11.27 \mathrm{~mm}$, and $13.8 \mathrm{~mm}$ for non-obese, Grade I, II, III, and morbid obese, respectively, p; 0.001). They conclude that obesity is an independent risk factor for epicardial fat deposition. ${ }^{23}$ So the striking difference in the basic characteristics between the two groups in this study by Kemal D et al. is what led to a higher sensitivity and specificity results.

\section{Study Limitation}

This study was not adjusted to the age and sex, considering the difficulty as age and male sex are unmodifiable independent risk factors for coronary artery disease events. However, after heterogeneity testing, age and sex variables could already be removed as confounding factors. Waist circumference could be a confounding factor because it is significantly higher in groups with coronary lesions, but it was removed as a confounding factor based on the heterogeneity test. This study still has another variable, namely cardiovascular risk factors that still show heterogeneous data after the heterogeneity test

\section{Conclusion}

In This study we observe Male, old age, the increased of waist circumference in both men and women, and the consumption of long-term antiplatelet and nitrate therapy are more common in patients with coronary lesions. HDL levels, mean overall waist circumference, mean waist circumference in women, mean overall thickness of epicardial fat, mean thickness of epicardial fat in normoweight, obese I and obese II were found higher in patients with coronary lesions. We also observe The cut-off value of epicardial fat thickness in this study was $2.835 \mathrm{~mm}$ with a good sensitivity and specificity value, and diagnostic ability.

\section{References}

1. Bornachea O, Veaa A, Llorente-Cortesa V. Interplay between epicardial adipose tissue, metabolicand cardiovascular diseases. Clinical Investigation of Arteriosclerosis. 2018:3-7.

2. Gaborit Bee, Sengenes C, Ancel P, Jacquier A, Dutour A. Role of Epicardial Adipose Tissue in Health and Disease: A Matter of Fat? Comprehensive Physiology. 2017;11:1060-69.

3. Nagy E, Jermendy AL, Merkely B, MaurovichHorvat P. Clinical importance of epicardial adipose tissue. Archieve of Med Science. 2016;13(4):858.

4. Eroğlu S. How do we measure epicardial adipose tissue thickness by transthoracic echocardiography? Anatolian Journal of Cardiology 2015;15:416-19.

5. Firdaus I. Angina pektoris dalam Panduan Praktik Klinis (PPK) dan Clinical Pathway (CP) Penyakit jantung dan Pembuluh darah. 1 ed. Jakarta: PERKI; 2016.

6. Cheng VY, Berman DS, Rozanski A, Dunning AM, Achenbach S, Al-Mallah M, et al. Performance of the traditional age, sex, and angina typicalitybased approach for estimating pretest probability of angiographically significant coronary artery disease in patients undergoing coronary computed tomographic angiography: results from the multinational coronary CT angiography evaluation for clinical outcomes: an international multicenter registry (CONFIRM). Circulation. 2011;124(22):2423-32, 1-8.

7. Jousilahti P, Vartiainen E, Tuomilehto J, Puska P. 
Sex, age, cardiovascular risk factors, and coronary heart disease: a prospective follow-up study of 14 786 middle-aged men and women in Finland. Circulation. 1999;99(9):1165-72.

8. Shemirani H, Khoshavi M. Correlation of echocardiographic epicardial fat thickness with severity of coronary artery disease-an observational study. Anadolu Kardiyol Derg. 2012;12:200-5.

9. Demir B, Demir E, Acıksarı G, Uygun T, Utku IK, Gedikbasi A, et al. The Association between the Epicardial Adipose Tissue Thickness and Oxidative Stress Parameters in Isolated Metabolic Syndrome Patients: A Multimarker Approach. International Journal of Endocrinology. 2014;2014:954045.

10. Ambrose JA, Barua RS. The Pathophysiology of Cigarette Smoking and Cardiovascular Disease An Update. Journal of the American College of Cardiology. 2004; $43^{10}: 1731-7$.

11. Yañez-Rivera TG, Baños-Gonzalez MA, BleCastillo JL, Torres-Hernandez ME, Torres-Lopez JE, Borrayo-Sanchez G. Relationship between epicardial adipose tissue, coronary artery disease and adiponectin in a Mexican population. Cardiovascular Ultrasound. 2014;12(35):1-6.

12. Kamal D, ElMoteleb AMA, Samir R, Saeed M. Epicardial fat thickness can predict severity and multivessel distribution in Egyptian patients with atherosclerotic coronary artery stenosis. The Egyptian Heart Journal. 2018;70:324-26.

13. Nabati M, Saffar N, Yazdani J, Parsaee MS. Relationship between Epicardial Fat Measured by Echocardiography and Coronary Atherosclerosis: A Single-Blind Historical Cohort Study. Echocardiography. 2013;30:506, 8-9.

14. Park J-S, Ahn S-G, Hwang J-W, Lim H-S, Choi B-J, Choi S-Y, et al. Impact of Body Mass Index on the relationship of epicardial adipose tissue to metabolic syndrome and coronary artery disease in an Asian population. Cardiovascular Diabetology. 2010;9(29):1-8.

15. Chaowalit N, Somers VK, Pellikka PA, Rihal CS, Lopez-Jimenez F. Subepicardial adipose tissue and the presence and severity of coronary artery disease. Atherosclerosis 2006;186:354-9.

16. Faghihi S, Vasheghani-Farahani A, Parsaee M, Saedi $S$, Ghadrdoost B. Association Between Epicardial Fat Thickness and Premature Coronary Artery Disease:
A Case Control Study. Research of Cardiovascular Medicine. 2015; $4^{2}: 1-6$.

17. Eroglu S, Sade LE, Yildirir A, Bal U, Ozbicer S, Ozgul AS, et al. Epicardial adipose tissue thickness by echocardiography is a marker for the presence and severity of coronary artery disease. Nutrition, metabolism, and cardiovascular diseases : NMCD. 2009;19(3):211-7.

18. El-Aziz WA, Ahmed M, Badr W. Association of echocardiographic epicardial fat with the extent of coronary artery disease. Menoufia Medical Journal. 2017;30:842-9.

19. Despre's J-P. Body Fat DIstribution and Risk of Cardiovascular Disease: An Update. Circulation. 2012;126:1301-13.

20. Willens HJ, Gomez-Marin O, Chirinos JA, Goldberg R, Lowery MH, Iacobellis G. Comparison of epicardial and pericardial fat thickness assessed by echocardiography in African American and nonHispanic White men: a pilot study. Ethnicity \& disease. 2008;18(3):311-6.

21. Adams DB, Narayan O, Munnur RK, Cameron JD, Wong DT, Talman AH, et al. Ethnic differences in coronary plaque and epicardial fat volume quantified using computed tomography. The international journal of cardiovascular imaging. $2017 ; 33^{2}: 241-9$.

22. Fox CS, White CC, Lohman K, Heard-Costa N, Cohen P, Zhang Y, et al. Genome-wide association of pericardial fat identifies a unique locus for ectopic fat. PLoS genetics. 2012;8(5):e1002705.

23. Jain S, Mahadevaiah M, Shivanagappa M. A Comparative Study of Epicardial Fat Thickness and its Association with Abdominal Visceral Fat Thickness in Obese and Nonobese Type 2 Diabetes Subjects. Journal of Cardiovascular Echography. 2015;25(4):103-7 